\title{
Impact of Water Abstraction on the Water Balance of Lake Ziway, Ethiopia
}

\author{
Demelash Wondimagegnehu Goshime 1,4,*, Alemseged Tamiru Haile ${ }^{2}$, Rafik Absi ${ }^{3}$ and Béatrice \\ Ledésert 1 \\ 1 Laboratory of Geosciences and Environment Cergy (GEC), University of Cergy-Pontoise, 95000 Neuville \\ Sur Oise, France; demewon21@gmail.com \\ 2 ECAM-EPMI Graduate School of Engineering, 95092 Cergy-Pontoise, France; r.absi@ecam-epmi.com \\ 3 Laboratory of Geosciences and Environment Cergy (GEC), University of Cergy-Pontoise, 95000 Neuville \\ Sur Oise, France; beatrice.ledesert@u-cergy.fr \\ 4 EBI School of Engineering, 49 Avenue des Genottes, 95895 Cergy-Pontoise, France \\ * Correspondence: demewon21@gmail.com; Tel: +251-923474480
}

\begin{abstract}
The available water volume of Lake Ziway in Ethiopia is declining at an alarming rate which hinders the lake services for a wide variety of sectors. However, there is a lack of systematic study to evaluate the contribution of water withdrawal by various sectors to the decline in the lake actual storage. In this study, we conducted a Water Abstraction Survey (WAS) to estimate actual water withdrawal from the lake. We applied a water balance model to evaluate the isolated impact of water withdrawal on the lake water volume and level. Three development pathways were simulated and the likely impact of these pathways on the lake water volume and level were assessed. Results indicate that water withdrawal for irrigation and domestic has significantly contributed to the change in the actual storage of Lake Ziway. Under full development pathways, irrigation water withdrawal from the lake is estimated to be $95.3 \mathrm{MCM}$. This will cause the mean annual water level of the lake to drop by $0.94 \mathrm{~m}$, which yield with $38 \mathrm{~km}^{2}$ reduction of the surface area of the lake. Overall, this will result in a reduction of mean annual lake volume by $405 \mathrm{MCM}$, which accounts for $26 \%$ of the average lake volume. Hence, our result indicates that the current impact of water abstraction on Lake Ziway storage is substantially large and will exacerbate in the future. This calls serious action on the management of water abstraction from the lake.
\end{abstract}

Keywords: Lake Ziway; Water balance; water abstraction; WAS; water volume ; Lake level

\section{Introduction}

Lake Ziway provides a wide variety of ecosystem services with significant contributions in the livelihoods of many people in the area. The lake is a vital source of water for irrigation, domestic, and fish supply for market in the country. Furthermore, the lake and its basin are the focus of the Ethiopian government to stimulate large scale export-oriented irrigated floriculture and a number of irrigation schemes. However, recent expansion of intensive water abstraction activities from the lake are leading water level drops. Hence, this will consequently damage the hydrological and ecological integrity of the lake [1].

Significant change has been observed in the water level of different Rift Valley Lakes in Ethiopia, as a result of both natural processes and human activities over the past decades. For instance, Seyoum et al. [2] showed that water level of Lake Abiyata significantly changed as a result of human activities. They reported 70\% (4.5 m) reduction in lake height between 1985 and 2006. A rise in the size and water level of Lake Awassa and Beseka was also reported in literature with the main cause of its variation is uncertain [3]. Jansen et al. [1] indicated annual average water level of Lake Ziway approximately decreased by $0.5 \mathrm{~m}$ as a result of recent expansion of irrigation activities around the lake and its tributaries. The authors also showed that this drop result in a tremendous decrease in the discharge of Bulbula River. 
The reduction in water level of Lake Ziway is mainly attributed to both natural and anthropogenic factors. Ayenew [4] estimated annual water abstraction for irrigation from the lake to be $28 \mathrm{Mm}^{3}$. However, recent studies reported that dramatic increase in water abstraction for horticulture and floriculture even doubles this value [1], [5]. The estimate of these studies was only from a dominant crop in the study area and results vary among different studies. However, sitespecific water abstraction surveys need to be performed to estimate actual water withdrawal. Desta et al. [5] assessed water abstraction of Lake Ziway by considering pump capacity and operation hour for all users. Then, they multiply these values by the number of pump to estimate the amount of water abstraction. However, it is unlikely to assume constant pump capacity and daily working hour for all water users in the study area. Therefore, a systematic study that takes in to account the spatial and temporal water abstraction is required to estimate actual irrigation water abstraction.

Several studies at global and local scales have indicated lack of data as a major challenge in the estimation of actual water abstracted for irrigation [6]. As such most of previous studies estimate irrigation water demand from a crop that requires the highest amount of water using national statistics, reports and climatic database [7-9]. However, recently remote sensing and field survey techniques are commonly applied by researcher to estimate irrigation water abstraction. The spatial and temporal coverage obtained from remote sensing data provides improvement in estimating water requirements. Note that field survey provides actual amount as it is based on actual measurement at field level.

The hydrology of many lakes has been relatively well documented, for instance that of, Lake Victoria [10], Lake Malawi [11], Lake Tana [12-15]. However, the hydrology of Lake Ziway is not well documented in scientific literature as compared to other lakes. Among the literature, on the hydrology of Lake Ziway [2,3,16-18] most of them focused on the water budget of the lake under the natural conditions. However, there is no study that quantitatively estimated actual water abstraction from the lake and its impact on the water level based on WAS. The exact magnitude of water withdrawal and its impact on the water level from available studies are uncertain. The absence of such knowledge in the study area will hinder the effective water management of the lake. Therefore, the aim of this study is to estimate water withdrawal from the lake and its impact on lake water level using water balance modelling approach.

\section{Study Area}

Lake Ziway is located in the Central Rift Valley (CRV) lakes basin of Ethiopia with a lake surface area covering $450 \mathrm{~km}^{2}$. It is situated between $7^{\circ} 25^{\prime} 30^{\prime \prime}$ and $8^{\circ} 34^{\prime} 30^{\prime \prime} \mathrm{N}$ and $38^{\circ} 12^{\prime} 00^{\prime \prime}$ and $39^{\circ} 15^{\prime} 00^{\prime \prime} \mathrm{E}$. Lake Ziway receives most of its water from Meki and Katar rivers, which drain the western and eastern plateaus, respectively. The two rivers account a total catchment area of $7020 \mathrm{~km}^{2}$. The outflow from Lake Ziway water is discharged into Bulbula River, which in turn flows to Lake Abiyata.

The climate in Lake Ziway is sub-humid to humid climatic, with mean annual temperature ranges from $13{ }^{\circ} \mathrm{C}$ to $27.5^{\circ} \mathrm{C}$. The mean annual rainfall varies from 454 to $995 \mathrm{~mm}$, with the highest rainfall occurring from June to September and lowest from October to January. Water abstractions from the lake for agricultural and domestic water demand account for the major water uses in the lake. The dominant land covers around the lake include agricultural cultivation, wetlands and water bodies (Figure 1). Figure 1 shows the location of Lake Ziway including contributing catchments. 


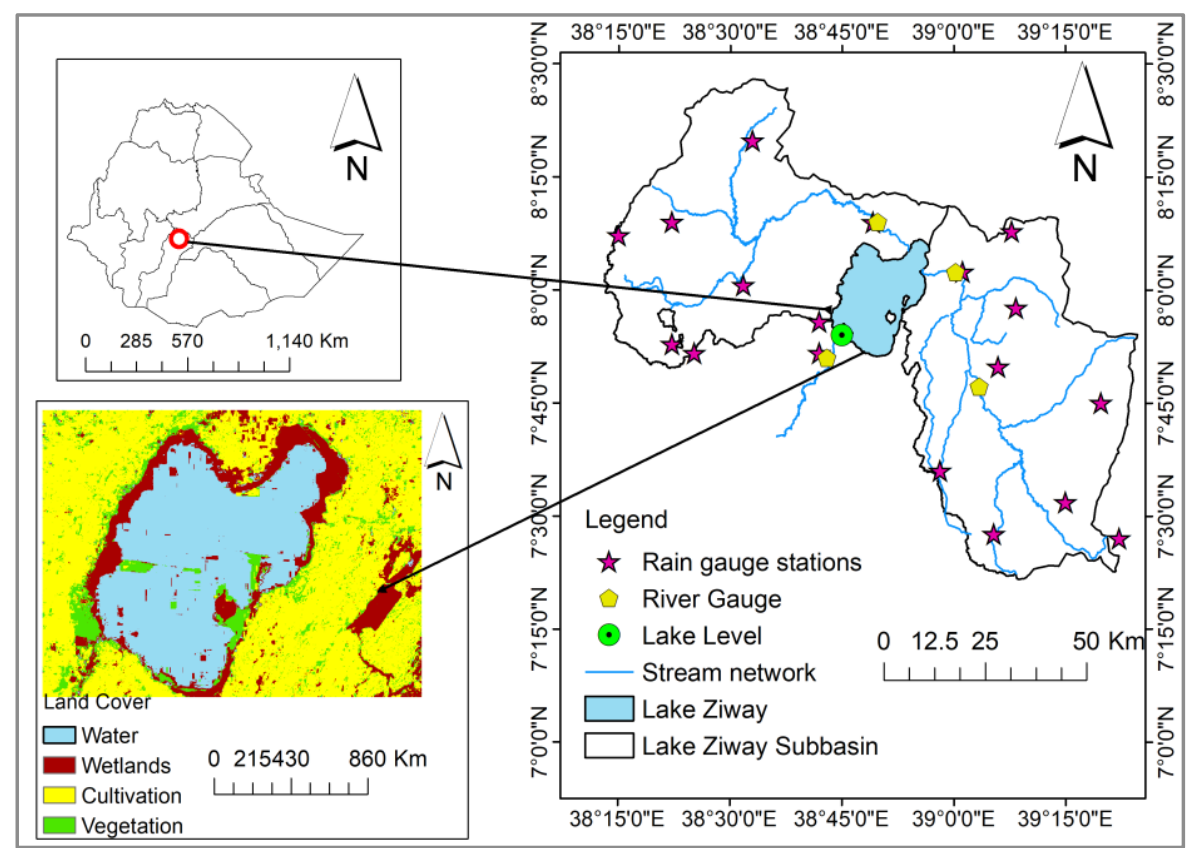

Figure 1. of Lake Ziway showing its catchment, major feeding rivers (Meki and Katar), raingauge stations, and land cover classification around the lake from Google Earth image.

\section{Datasets}

In this study, we used climate, hydrological and water abstraction data sets. The observed climate data sets were obtained from the National Meteorological Agency of Ethiopia and Climate Hazards Group Infrared Precipitation (CHIRP) satellite-only product at (daily temporal and $5.5 \mathrm{~km}$ spatial resolutions) extracted from http://chg.geog.ucsb.edu/data/. CHIRP covers regions that are situated between $50^{\circ} \mathrm{S}-50^{\circ} \mathrm{N}$ latitude and all longitudes $[19,20]$.

Lake Ziway water level, outflow (at Kerkersitu) and river discharge (at Meki and Katar Rivers) data were obtained from the Ethiopian Ministry of Water, Irrigation and Electricity of Ethiopia. The lake level-area-volume bathymetric survey conducted by the Ministry of Water, Irrigation and Electricity of Ethiopia in 1984 and 2013 were used for water level simulation.

Water abstraction data around Lake Ziway was collected from water abstraction survey at field level for 15 days from 20/10/2018 to 05/11/2018 around the lake. This period was selected because the problem associated with water resources in the area usually occur in the dry season. This is mainly water user start to irrigate more water during this period and feasible for field measurement. Although, the field survey was conducted during dry season we interviewed the user there seasonal water use for accurate water abstraction estimation.

The field survey was performed with a GPS device, bucket, measurement tape, current meter, and stopwatch. In addition, the data was upgraded by additional data obtained from water and agricultural offices of the localities in the study area. The facilities for water abstraction include individual farmers pumping points, water diversion schemes, flower farms, and domestic water supply owned by individuals, community and private sectors. We also surveyed seasonal pump and/or scheme operation, crop types, command area and irrigation scheduling for season irrigation pattern throughout the year.

\section{Methods}

This study is based on the assessment of existing and satellite hydro-meteorological dataset, water abstraction survey, and review of published studies. We applied the hydrological model output coupling with water balance modelling and field surveys. The hydrological model output was based on calibrated and validated results from Goshime et al. [21].The methodologies followed in this study are: First, we estimated water abstraction for all abstraction points based on Water 
Abstraction Survey (WAS). Next, we evaluated the water balance components of the lake under the natural condition on a monthly time steps. Then, the implication of existing and future water abstraction on the water level was evaluated using a water balance modelling approach. The simulated lake level for the natural condition was used as a reference to evaluate the impact of water abstraction on the water level and volume.

\subsection{Impact of Water Abstraction}

A record of water abstraction volume is not available at abstraction points in the study area. Hence, we measured the amount of water abstraction for selected abstraction points and managers were interviewed based on our data collection format. The amount of water abstracted was measured using a bucket with a known size. The time which is elapsed to fill the bucket was recorded and was used to estimate the capacity of the pump in volume per unit time. The equation reads:

$$
Q_{a b s}=Q d \times n \times h
$$

where $Q_{a b s}$ is the amount of water abstracted $\left(\mathrm{m}^{3}\right), \mathrm{n}$ is a number of pumps used by the user, $Q d$ is the diverted discharge of the pump $\left(\mathrm{m}^{3} \mathrm{~s}^{-1}\right)$, and $\mathrm{h}$ is abstraction operation duration (s).

We measured the water abstraction for the pumps which were under operation during our field survey. However, the characteristics of all pumps were recorded and used to extrapolate using the sampled abstraction rates, pump type and size. The rate of water abstraction was assumed to be constant throughout the year. However, we estimated the monthly seasonal water abstraction based on irrigation pattern and pump operation condition.

\subsection{Lake Water Level Simulation}

The inflow and outflow water balance components of the lake were expressed using the following relationships at monthly time steps including water abstraction:

$$
\Delta V=R(t)-E(t)+Q_{\text {in }}(t)-Q_{\text {out }}(t)-Q_{a b s}
$$

where $\Delta V$ is the change in lake water volume, $R$ is rainfall over the lake surface and $E$ is evaporation from the lake surface, $Q_{i n}$ is surface water inflow to the lake, $Q_{o u t}$ is surface water outflow from the lake, and $Q_{a b s}$ is water abstraction from the lake. All terms are in $\mathrm{m}^{3} \mathrm{month}^{-1}$ unit.

In this study, lake areal rainfall is estimated from bias-corrected CHIRP rainfall estimate using rain gauge dataset as a reference. For a more detailed analysis of a bias correction approach see Goshime et al. [21]. Lake open water evaporation was estimated from three representative stations (i.e., Ziway, Ogolcho and Arata) which are located close to the lake using Penman [22] method.

The surface inflow to the lake from Meki and Katar river gauge stations simulated using Hydrologiska Byråns Vattenbalansavdelning (HBV) hydrological modelling output based on our prevouis studies, see Goshime et al. [21]. The ungauged inflow contribution was estimated using the area-ratio method. Lake Outflow discharge available at the Kekersitu station was directly used in the water balance.

After all water balance terms estimated a spread sheet water balance model is developed to simulate lake volume as follows:

$$
\mathrm{V}_{\text {lake }}(\mathrm{t})=\mathrm{V}_{\text {lake }}(\mathrm{t}-1)+\Delta \mathrm{V}
$$

where $V_{\text {lake }}(t)$ is the lake volume at time $t, V_{\text {lake }}(t-1)$ is lake volume at a previous time $(t-1)$, and $\Delta V$ represents a change in lake volume as estimated using Equation (2). The lake volume was then converted to lake level using the bathymetric relationships.

\subsection{Impact of Water Abstraction}

To evaluate the impact of water abstraction, three scenarios were built: existing development (ED), likely future development (LD) and full development potential (FD) inaddition to the baseline natural (BS). The main required data for scenario development was obtained from WAS, Rift Valley lakes basin master plan, feasibility studies and administrative regional water office. First, we 
estimated the amount of water abstraction for existing development scenario based on water abstraction survey. Then, the amount of water abstraction for likely future and full planned development scenario was interpolated from existing development (ED) scenario based on the area of the scheme for corresponding scenario.

The BS is the natural simulated water level from 1986-2000 without water abstraction. Whereas, for ED, LD and FD scenarios 2000, 3100 and 5000 ha of irrigate land withdrawing water from the lake. For this, first we assessed the lake water balance without and with water abstraction component ( $\left.Q_{a b b}\right)$ included in Eqnuation (2). Then, we simulated the lake volume (corresponding lake level) for the baseline natural condition and scenario development using Eqnuation (3). The isolated impact of water withdrawal from the lake on the water level will be estimated from the net difference between the simulated for natural and scenario condition.

\section{Results and Discussion}

\subsection{Water Abstraction}

The estimated amounts of annual water abstraction for surveyed water sectors are given in Figure 2. The water uses from individual smallholder farmers were summed up into three administrative districts. The figure shows that Sher Ethiopia flower farm, Meki-Ziway pump irrigation and smallholder individual farmers at three districts were the major water users from the lake. The survey shows that water abstraction for irrigation accounts for $97 \%$ and only $3 \%$ accounts for domestic water use. We surveyed a total of 856 pumping stations of the individual farmers, 4 irrigation schemes, 7 flower farms, and 1 water supply facility. The domestic water supply in Ziway town was estimated to be $1.26 \mathrm{Mm}^{3}$ per year over the study period (personal office communication).

The amount of annual water withdrawal from the lake for irrigation and domestic purpose revealed $38 \mathrm{Mm}^{3}$ volume of water to irrigate 2000 ha of agricultural lands for three seasons per each year. This value is slightly lower than estimated in Desta et al. [5] $\left(41 \mathrm{Mm}^{3}\right)$ but higher than in Ayenew [4] $\left(28 \mathrm{Mm}^{3}\right)$. The difference on the amount of estimated water abstraction among the studies arise from the methods and assumptions applied to estimate. In this study, we used more precise data from water abstraction survey whereas previous studies simply applied from a highest crop water requirement in the area.

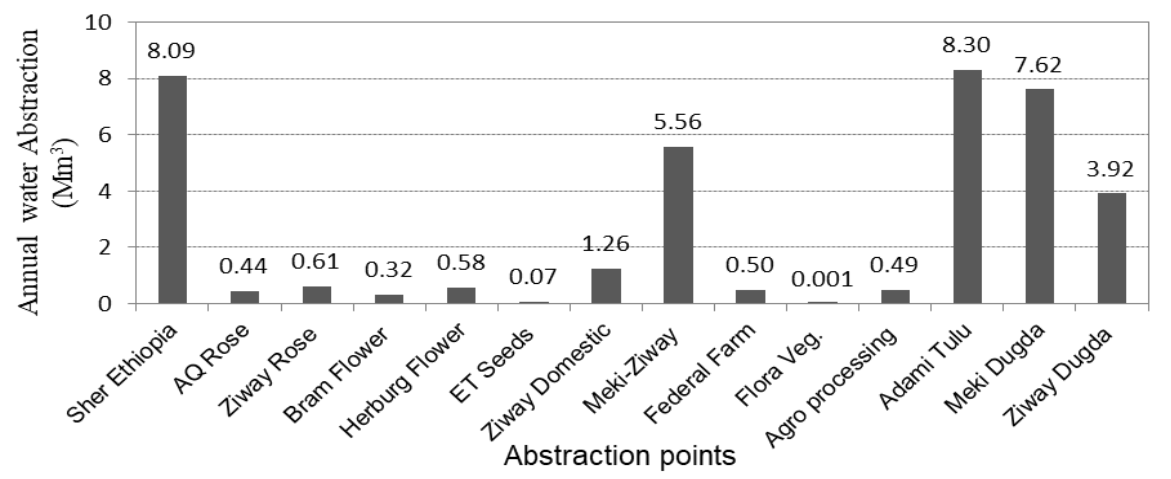

Figure 2. Annual water abstraction amount for the existing situation for all considered water sectors. The total annual water withdrawal makes $38 \mathrm{Mm}^{3}$ per year.

If all the planned irrigated areas are fully implemented, the estimated annual water abstraction will increase to $95.3 \mathrm{MCM}$. The monthly water abstraction estimated for all scenarios were presented in Figure 3. 


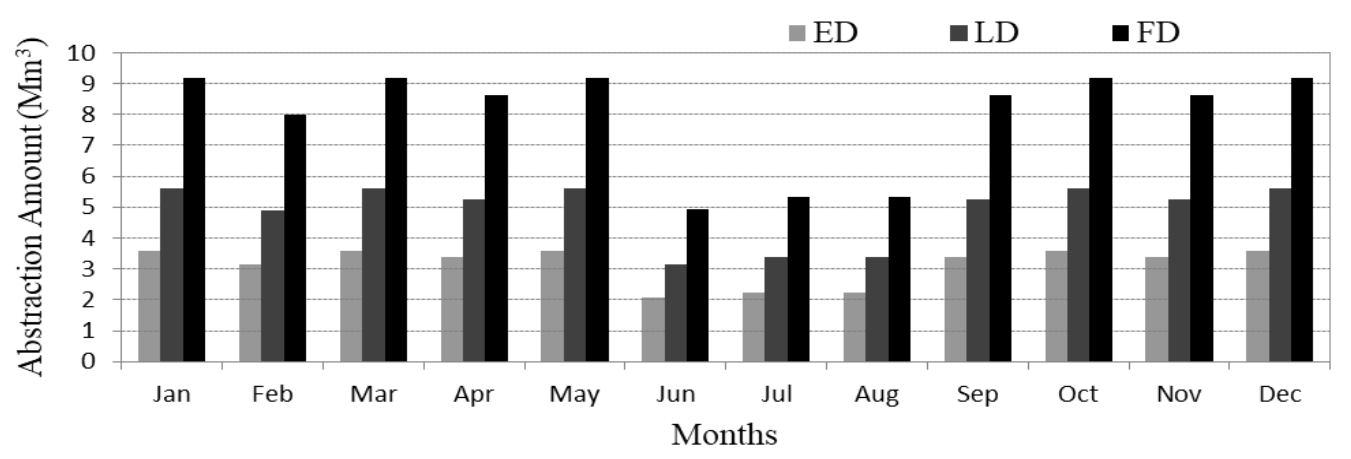

Figure 3. Estimate of Monthly water abstraction for existing (ED), Medium (LD) and Future (FD) scenarios.

\subsection{Lake Water Balance.}

The monthly average simulated water balance components of Lake Ziway from 1986 to 2000 result revealed that rainfall, river inflow and evaporation constitute 33, 60 and $83 \%$ of the annual water balance of the lake, respectively. This indicates that the river inflow contributes the major Lake inflow and evaporation over the lake surface accounts the major lake water loss.

The results of annual lake water balance for the natural condition (1986-2000) for Lake Ziway are given in Table 1 . The finding of this study was compared with other previous studies $[1,4,5,18]$. We note that our estimates of the annual water balance components are comparable with most of the studies.

Table 1. Annual water balance terms of Lake Ziway for the natural condition in $\mathrm{Mm}^{3}$ for 1986-2000.

\begin{tabular}{ccccccccc}
\hline & \multicolumn{3}{c}{ Inflow } & \multicolumn{3}{c}{ Outflow } & \multicolumn{2}{c}{ Water Abstraction } \\
\cline { 2 - 9 } Water Balance & $\mathrm{R}$ & $\mathrm{QM}_{\mathrm{M}}$ & $\mathrm{QK}_{\mathrm{K}}$ & QU & Evap & Qut $_{\text {out }}$ & Irrigation & Domestic \\
\hline This study & 338 & 233 & 380 & 81 & 832 & 171 & 37 & 1.26 \\
\hline Vallet-Columb et al. [18] & 335 & 273 & 418 & 50 & 832 & 157 & - & - \\
\hline Ayenew [4] & 323 & 265 & 392 & 48 & 890 & 184 & 28 & - \\
\hline Jansen et al. [1] & 327 & 274 & 411 & - & 774 & 185 & 27 & 1.31 \\
\hline Desta et al. [5] & 356 & 262 & 394 & - & 854 & - & 41 & - \\
\hline
\end{tabular}

Note: $R$, rainfall on the lake; $\mathrm{Q}_{\mathrm{M}}$, Meki river inflow and $\mathrm{Q}_{\mathrm{K}}$, Katar river inflow; $\mathrm{Qu}$, inflow from ungauged catchment; Evap, evaporation from the lake surface, and Qout, lake outflow in the river outlet.

\subsection{Lake Water Level Simulation}

After all water balance components estimated, we developed a water balance model to simulate the lake water volume using Equation (3). The simulated lake volume was then transformed into a lake water level using area-elevation-storage bathymetric relationships. The simulated lake levels were compared with observed lake levels. Figure 4 shows the simulated and observed lake levels for 1986-2014 on a monthly time step. The simulated monthly lake levels reasonably fit the pattern of observed water level up to 2000. However, for a recent period (after 2000) the simulated lake level significantly deviated from the observed counterparts. The deviation between the simulated and observed levels beginning from the end of 2000 attributed to an error in any of the water balance terms and human activities (e.g., pumping water abstraction for irrigation) which are not incorporated in our model simulation. We also refer to previous studies that indicated increased irrigation water abstraction during recent periods in the Central Rift Valley lakes basin $[5,23]$. Hence, the time series prior to the year of the deviation (i.e., 1986-2000) was considered as the baseline natural period to evaluate the impact of water abstraction on the water level.

The figure also illustrates the behaviour of maximum and minimum temperature trend to the water level fluctuation. We note that, most of the time the trend of temperature variation followed 
the pattern of water level fluctuation (Figure 4). Hence, there is a dependence of the lake hydrology on the future global warming related to slightly decreasing precipitation trend, increasing air temperature and evaporation trend, leading to decline in lake water levels as well as water scarcity problems.

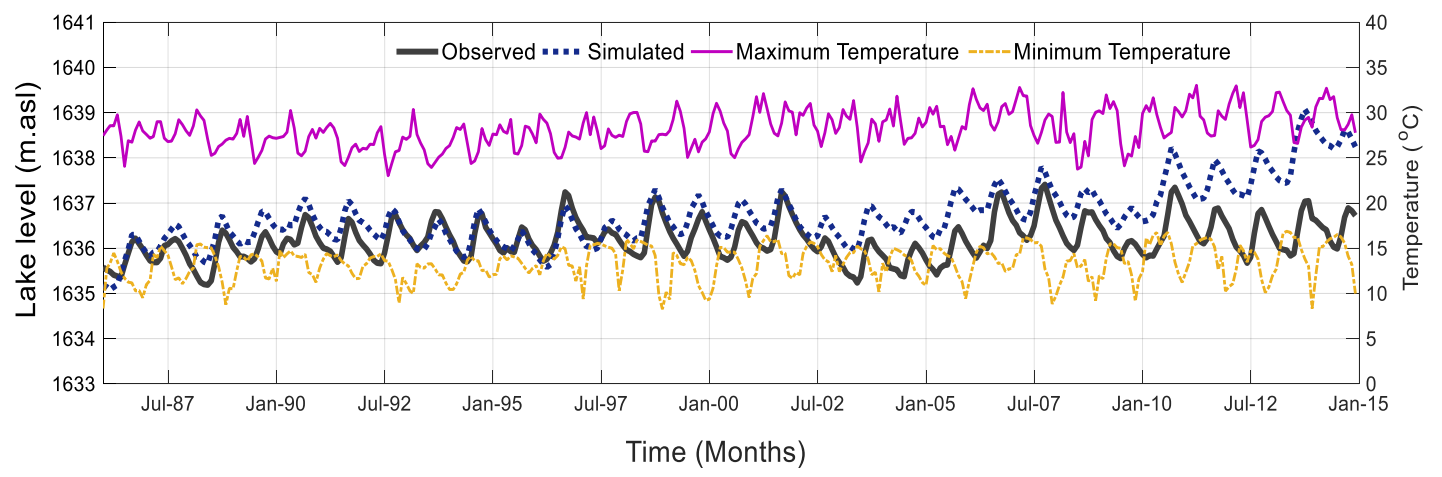

Figure 4. Comparison of observed and simulated lake level for the period 1986 to 2014.

Figure 5 shows the result of lake level simulation for baseline condition (1986-2000) and the simulation including water abstractions for the three scenarios. The simulated monthly water level for the three scenarios was not reasonably followed the baseline lake level over the simulation period. The disagreement was significant after 1990 onwards, which indicate increasing cumulative water abstraction. The lake water level change for existing development (ED) is relatively lower than as compared to other pathways. During this pathway, the average annual water level of the lake is $1635.82 \mathrm{~m}$.a.s.l, this will lead to $0.36 \mathrm{~m}$ decline in lake level from the baseline. The surface area of the lake for this pathway is $424 \mathrm{~km}^{2}$, which accounts for $4 \%$ reduction in lake surface area (Table 2). Under likely future development pathway (LFD) the mean water level reach 1635.61 m.a.s.l and mean lake surface area is reduced from 442 to $416 \mathrm{~km}^{2}$, which resulted in mean annual water level to be lowered by $0.57 \mathrm{~m}$ from the baseline (Table 2).

The summary of the average annual water level, surface area and volume for natural level and each development scenario condition are presented in Table 2 . The result indicates the mean annual lake level, volume and surface area decreased during water abstraction for development scenario. For existing water abstraction, the average annual surface area of the lake lowered by $18 \mathrm{~km}^{2}$ (Table 2). This consequently will result in $162 \mathrm{Mm}^{3} \mathrm{y}^{-1}$ reductions in the volume of the lake, which accounts for $11 \%$ of the average lake volume from the baseline (Table 2). For likely future development scenario (LD) the mean annual volume to be lowered by $16.4 \%$ from the baseline (Table 2).

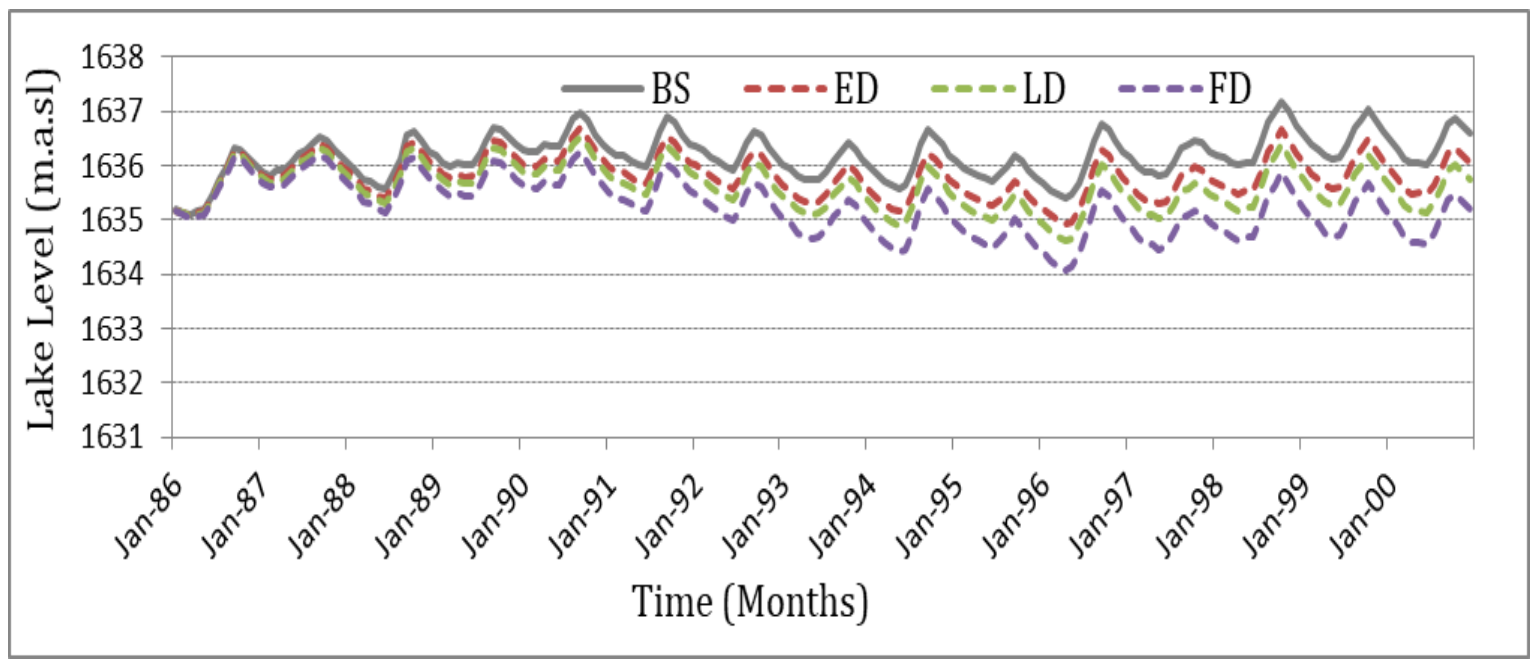


Figure 5. Comparison of baseline (natural condition) and simulated lake level for three scenarios including water abstraction from Lake Ziway from 1986-2000.

However, the change is substantial if all proposed full development scenario (FD) was implemented. During this scenario, the mean annual lake water level is reduced by $0.94 \mathrm{~m}$ from the baseline.The decrease in water level of the lake in some dry years even drops up to $1.08 \mathrm{~m}$ from the natural water level. Hence, this will likely to have significant impact on the ecology of the lake and reduce its services for a wide variety of ecosystems. Lake Ziway supports the largest fish stock in the CRV basin and serve as a principal source of commercial fishing in Ethiopia [24]. Hence, the reduction in water volume will hinder its potential as a freshwater fishery which in turn reduces the main economic income of the country. The impact also goes to reduce its service for food and shelter for a wide variety of endemic birds and wild animals [24].

Table 2. Summary of simulation results for each pathway from 1986-2000.

\begin{tabular}{ccccccc}
\hline Scenario & \multicolumn{2}{c}{ Mean annual lake balance term } & \multicolumn{3}{c}{ Change from the baseline } \\
\hline & $\begin{array}{c}\text { Water Level } \\
\text { (m.a.s.l) }\end{array}$ & $\begin{array}{c}\text { Area } \\
\left.\mathbf{( k m}^{2}\right)\end{array}$ & $\begin{array}{c}\text { Volume } \\
\mathbf{( M C M )}\end{array}$ & $\begin{array}{c}\text { WL } \\
\text { Change (m) }\end{array}$ & $\begin{array}{c}\text { Area change } \\
\mathbf{( \% )}\end{array}$ & $\begin{array}{c}\text { Volume } \\
\text { change (\%) }\end{array}$ \\
\hline BS & 1636.18 & 442.24 & 1529.50 & & & \\
ED & 1635.82 & 424.35 & 1367.49 & -0.36 & -4.0 & -10.6 \\
LD & 1635.61 & 415.49 & 1278.53 & -0.57 & -6.1 & -16.4 \\
FD & 1635.25 & 403.95 & 1124.10 & -0.94 & -8.7 & -26.5 \\
\hline
\end{tabular}

Note: BS, Baseline natural; ED = Existing development; LD is likely future development and FD is full planned development pathway.

In this study, we focused on the impacts of direct water abstraction from Lake Ziway on the water level. Desta et al. [5] reported that a number of human-induced impacts, such as sediment loads due to deforestation, soil erosion, uncontrolled water abstractions from the lake and its feeding rivers are main causes for the lake water level reduction. Our result also share the view of their studies that water abstraction contributed to the observed drops in Lake water level. Hence, if the current water abstraction situations continue without intervention, the lake will lead to vulnerable to excessive water scarcity problem as that has been observed in Lake Alemaya [25]. Therefore, consideration should be given to determine how the water is appropriately utilized. This requires integrated management of water abstraction among all water sectors in the study area.

\section{Conclusions}

In this study, we evaluated the actual water withdrawal from the lake and its impact on the water level using a water balance modelling approach. The study was unique as we applied field water abstraction survey coupling calibrated hydrological model output and water balance model. The bias-corrected CHIRP rainfall dataset was used as input in a rainfall-runoff simulation where the simulated river inflow served as input to the water balance model. A water abstraction survey (WAS) was conducted to estimate actual water withdrawal from the lake.

This study indicated that an accurate estimate of actual water withdrawal and its impact on the water level can be estimated using WAS and water balancing approach, respectively. As a result of $37 \mathrm{Mm}^{3}$ annual water withdrawals from the lake for irrigation, the mean water level and volume of Lake Ziway drop by $0.36 \mathrm{~m}$ and $162 \mathrm{Mm}^{3}$, respectively. If full planned development pathway to be implemented the water level and surface area of the lake drop by an additional $0.37 \mathrm{~m}$ and $11 \mathrm{~km}^{2}$, respectively. This consequently will yield to a significant reduction in the volume of the lake by 405 MCM, which accounts for $26 \%$ reduction of average lake volume. Hence, this study indicates that water abstraction directly from the lake has a significant impact on the water level, volume and surface area of the lake. The water level change also further reflected in the temporal variation on the climate change trend. Therefore, we suggest the need for integrated water abstraction management 
among all sectors towards achieving sustainable water use around the lake including future climate change.

Acknowledgments: This study is part of PhD thesis of the first author supported by Ethio-France sandwich program. The authors also acknowledge Central Rift Valley lakes basin authority field office and data collector for their help during data collection. We are also grateful to the Ministry of Water, Irrigation and Electricity and National Meteorological Agency of Ethiopia for making various data available.

Author Contributions: All authors initiated the original idea of the study.Demelash Wondimagegnehu Goshime was responsible for data survey and to draft the manuscript. Rafik Absi,Alemesged Haile and Béatrice Ledésert edited the draft manuscript and supervised the research work. All authors read and approved the final manuscript.

Conflicts of Interest: The authors declare no conflict of interest.

\section{References}

1. Jansen, H.C., Hengsdijk, H., Legesse, D., Ayenew, T., Hellegers, P. \& Spliethoff, P.C., Land and water resources assessment in the Ethiopian Central Rift Valley: project: ecosystems for water, food and economic development in the Ethiopian Central Rift Valley. Alterra report 1587, Wageningen, 2007.

2. Seyoum, W.M., Milewski, A.M. \& Durham, M.C., Understanding the relative impacts of natural processes and human activities on the hydrology of the Central Rift Valley lakes, East Africa: Assessment of natural and human impacts on the hydrology of lakes. Hydrol. Process. 2015, 29(19), 4312-4324.

3. Ayenew, T., Water management problems in the Ethiopian rift: challenges for development. J. Afric. Earth Sci. 2007, 48 (2/3), 222-236.

4. Ayenew, T., Environmental implications of changes in the levels of lakes in the Ethiopian Rift since 1970. Reg. Environ. Change. 2004, 4(4), 192-204.

5. Desta, H., Lemma, B. \& Gebremariam, E., Identifying sustainability challenges on land and water uses: The case of Lake Ziway watershed, Ethiopia. Appl. Geog. 2017, 88, 130-143.

6. Döll, et al., Impact of water withdrawals from groundwater and surface water on continental water storage variations. J. Geodyn, 2012, 59-60, 143-156.

7. Adgolign, T.B., Rao, G.V.R.S. \& Abbulu, Y., WEAP modeling of surface water resources allocation in Didessa Sub-Basin, West Ethiopia. Sustain. Water Resour. Manag. 2015, 2(1), 55-70.

8. Chinnasamy, P., Bharati, L., Bhattarai, U., Khadka, A. \& Wahid, S., Impact of planned water resource development on current and future water demand in the Koshi River basin, Nepal. Water International. 2015,8060 .

9. Alemayehu, T., McCartney, M., Kebede, S., Modelling to evaluate the water resource implications of planned infrastructure development in the Lake Tana sub-basin, Ethiopia. Ecohydrol. \& Hydrobio. 2010, 10, 211-221.

10. Nicholson, S.E. \& Yin, X., Rainfall conditions in equatorial East Africa during the nineteenth century as inferred from the record of Lake Victoria. Climate Change.2001, 48(2-3), 387-398.

11. Kumambala, P.G., Water Balance Model of Lake Malawi and its Sensitivity to Climate Change. J. Hydrol. 2010, 4(1), 152-162.

12. Dessie et al., Water balance of a lake with floodplain buffering: Lake Tana, Blue Nile Basin, Ethiopia. J. Hydrol. 2015, 522, 174-186.

13. Rientjes, T.H.M., Perera, B.U.J., Haile, A.T., Reggiani, P. \& Muthuwatta, L.P., Regionalisation for lake level simulation-the case of Lake Tana in the Upper Blue Nile, Ethiopia. Hydrol Earth Syst Sci.2011, 15(4), 11671183.

14. Wale, A., Rientjes, T.H.M., Gieske, A.S.M. \& Getachew, H.A., Ungauged catchment contributions to Lake Tana's water balance. Hydrol. Process .2009, 23(26), 3682-3693.

15. Kebede, S., Travi, Y., T. Alemayehu, T. \& Marc, V., Water balance of Lake Tana and its sensitivity to fluctuations in rainfall, Blue Nile basin, Ethiopia. J. Hydrol. 2006, 316(1-4), 233-247.

16. Abraham, L. Z., Climate change impact on Lake Ziway watershed water availability, Ethiopia. Catchment and Lake research. 2006, 3.

17. Legesse, D., Vallet-Coulomb, C. \& Gasse, F., Hydrological response of a catchment to climate and land use changes in Tropical Africa: Case study south central Ethiopia. J. Hydrol. 2003, 275(1-2). 67-85. 
18. Vallet-Coulomb, C., Legesse, D., Gasse, F., Travi, Y. \& Chernet, T., Lake evaporation estimates in tropical Africa (Lake Ziway, Ethiopia). J. Hydrol. 2001, 245(1-4),1-18.

19. Funk, C., Verdin, A., Michaelsen, J., Peterson, P., Pedreros, D. \& Husak, G., A global satellite-assisted precipitation climatology. Earth Syst. Sci. Data. 2015, 7(2), 275-287.

20. Funk et al., A quasi-global precipitation time series for drought monitoring, US Geological Survey Data Series. 2019, 832(4), 1-12.

21. Goshime, D. W., Absi, R. \& Ledésert., Evaluation and bias correction of CHIRP rainfall estimate for rainfallrunoff simulation over Lake Ziway watershed, Ethiopia. Hydrol. 2019, 6(3), 68.

22. Penman, H.L., Natural Evaporation from Open Water, Bare Soil and Grass. Proc. Roy. Soc. A: Math. Phys. Eng. Sci. 1948, 193(1032), 120-145.

23. Desta, H. \& Lemma, B., SWAT based hydrological assessment and characterization of Lake Ziway subwatersheds, Ethiopia. J. Hydrol.: Reg. Stud. 2017, 13, 122-137.

24. Ayenew, T. \& Legesse, D., The changing face of the Ethiopian rift lakes and their environs: call of the time. Lakes E Reservoirs: Resear Manag. 2007, 12(3), 149-165.

25. Alemayehu, T., Furi, W. \& Legesse, D., Impact of water overexploitation on highland lakes of eastern Ethiopia. Environ. Geolo. 2007, 8.

(C) 2019 by the authors; licensee MDPI, Basel, Switzerland. This article is an open access article distributed under the terms and conditions of the Creative Commons by Attribution (CC-BY) license (http://creativecommons.org/licenses/by/4.0/). 